\title{
PATHOGENICITY DETERMINANTS AND \\ ANTIBIOTIC RESISTANCE PROFILES OF ENTEROCOCCI FROM FOODS OF ANIMAL ORIGIN IN TURKEY
}

\author{
Tulay Elal Mus ${ }^{1 *}$, Figen CetinkaYA ${ }^{2}$, Recep CibiK $^{2}$, Gul Ece SoyUtemiz ${ }^{2}$, \\ Husniye SIMSEK $^{3}$ and Nilay COPLU ${ }^{4}$ \\ ${ }^{1}$ Department of Food Processing, Vocational School of Keles, University of Uludag, \\ Bursa, Turkey; ${ }^{2}$ Department of Food Hygiene and Technology, Faculty of Veterinary \\ Medicine, University of Uludag, Bursa, Turkey; ${ }^{3}$ Department of Microbiology Reference \\ Laboratories, Public Health Institution of Turkey, Ankara, Turkey; ${ }^{4}$ Department of \\ Clinical Microbiology, Ministry of Health, Diskapi Research and Training Hospital, \\ Ankara, Turkey
}

(Received 22 February 2017; accepted 6 November 2017)

In this study, the presence of genes responsible for the pathogenicity and antibiotic resistance profile of enterococci isolated from various foodstuffs of animal origin was investigated. The percentage prevalence of enterococci was $54.1 \%(203 / 375)$ and the average count was found to be $3.81 \mathrm{log} \mathrm{cfu} / \mathrm{ml}-\mathrm{g}$. Species-specific primers revealed Enterococcus faecalis as the predominant species carrying one or more virulence-associated traits of efa, gelE, ace, esp and agg genetic markers. Only one E. faecium isolate (from milk) was positive for the esp gene. Regarding antibiotic resistance, the highest frequency of resistance was observed for tetracycline $(21.7 \%)$, followed by quinupristin/dalfopristin $(13.3 \%)$, ciprofloxacin $(2.0 \%)$, penicillin $(2.0 \%)$, linezolid $(1.0 \%)$, ampicillin (1.0\%), streptomycin $(1.0 \%)$, and gentamicin $(0.5 \%)$. Enterococcus faecalis showed a higher prevalence of antibiotic resistance than other enterococci. The percentage of multidrug resistance among the isolates was $3.4 \%$. Twenty-nine E. faecalis isolates (26.6\%) carrying one of the virulence-associated traits were at the same time resistant to at least one antibiotic. Our results show that foods of animal origin, including ready-to-eat products, may be reservoirs of antibiotic-resistant and potentially virulent enterococci.

Key words: Food, enterococci, incidence, antibiotic resistance, virulence genes

Enterococci are indicator bacteria of possible faecal contamination and are isolated frequently from food, plants, water and soil. They are included in different types of cheese and fermented meat products to improve organoleptic quality and to extend shelf life during production (Pesavento et al., 2014). It has been

*Corresponding author; E-mail: tulay_elal@yahoo.com; Phone: 0090 (224) 861-3425; Fax: 0090 (224) 681-3521 
documented that some strains of enterococci, especially E. faecium, may inhibit the growth of food-borne pathogens in fermented foods (Barbosa et al., 2014). The probiotic potential of some enterococcal strains is being successfully applied to improve human or animal health (Pieniz et al., 2015). Furthermore, the commercial E. faecium NCIMB 10415 strain $\left(\right.$ Cylatin $^{\circledR}$ ) has been safely used in livestock rearing and fattening (EFSA, 2013a).

Enterococci were not recommended in the QPS (qualified presumption of safety) list by the European Food Safety Authority (EFSA) because of their potential role in human clinical infections associated with endocarditis, bacteraemia, urinary tract infections and antimicrobial resistance (EFSA, 2013b). Antimicrobial resistance, especially multidrug resistance, is one of the main public health concerns due to treatment failures of infections, particularly in immunosuppressed individuals (Fisher and Phillips, 2009; Pesavento et al., 2014). Enterococcus species have an intrinsic resistance to several antibiotics such as streptogramins and beta-lactams. Mobile genetic elements were found to be responsible for acquired resistance to glycopeptides, tetracyclines, lincosamides, macrolides and aminoglycosides in enterococci isolated from different sources including livestock and food strains (Hollenbeck and Rice, 2012). Adhesion and secreted virulence factors are the main pathogenicity factors of enterococci. Aggregation substance (agg), extracellular surface protein (esp), Enterococcus faecalis antigen $(e f a \mathrm{~A})$, adhesin to collagen (ace), endocarditis and biofilm-associated pili (ebp) are the major adhesion factors. Secreted enterococcal virulence factors are cytolysin (cyl), gelatinase ( $g e l \mathrm{E})$ and hyalorinidase (hyl) (Kafil et al., 2013; ChajeckaWierzchowska et al., 2017). The safety assessment of enterococcal strains is a complicated task because of their possession of highly prevalent virulence and antimicrobial resistance traits (Klibi et al., 2013).

Enterococci may show tolerance to antimicrobial pressure because of their ability to easily acquire resistance to new classes antimicrobials by expressing new resistance genes. Antimicrobial-resistant enterococci may be present in foods of animal origin, and these foods may be responsible for the transmission of resistant bacteria to humans through consumption. Transfer of the streptomycin resistance gene (aadA) of $\mathrm{E}$. faecium from a food strain into a clinical strain by class 1 integron has been reported recently (Jahan et al., 2015). Although enterococci were considered non-pathogenic for a long period of time, over the last few decades they have been recognised as one of the most common emerging nosocomial pathogens, causing a mortality rate of up to 61\% (Fisher and Phillips, 2009).

In the present study, enterococci isolated from foodstuffs of animal origin (including ready-to-eat products) were tested for the presence of virulence genes including agg, esp, ace, gelE and $e f a$. The antimicrobial susceptibility profiles of the isolates were also determined. 


\section{Materials and methods}

\section{Food sampling}

A total of 375 samples of foods of animal origin, including 150 milk/dairy product, 150 meat/meat product and 75 chicken/poultry product samples, were collected from several supermarkets, delicatessens and open bazaars in the Marmara Region of Turkey. These consisted of 180 raw food samples (20 milk, 30 meat, 30 minced meat, 25 meatball, 65 chicken meat and 10 poultry product samples such as nugget and schnitzel) and 195 ready-to-eat food samples (85 cheese, 15 yoghurt, $15 \mathrm{kefir}, 15$ butter, 25 soujuk, 20 pastrami and $20 \mathrm{salami} /$ sausage samples). The samples were immediately transported to the laboratory under refrigerated conditions. All microbiological analyses were performed within the same day.

\section{Bacterial isolation}

A 10-g quantity of each food sample was homogenised in $90 \mathrm{ml}$ of pepton water. Decimal dilutions were streaked onto Slanetz and Bartley agar (CM0377, Oxoid, UK) plates and incubated at $37^{\circ} \mathrm{C}$ for two days. After incubation, pinkand brown-coloured colonies were subjected to Gram staining, PYR test, esculin hydrolysis and growth at 10 and $45{ }^{\circ} \mathrm{C}$, in $6.5 \% \mathrm{NaCl}$ and at $\mathrm{pH} 9.6$. The isolates were preserved in Brain Heart Infusion broth (CM1135, Oxoid, UK) supplemented with $20 \%$ glycerol at $-20{ }^{\circ} \mathrm{C}$ for further experiments.

\section{Antibiotic susceptibility and MIC testing}

The antibiotic susceptibility of the strains was evaluated by the disk diffusion method according to the recommendations of the Clinical and Laboratory Standards Institute (CLSI, 2014). Penicillin (10 U), ampicillin (10 $\mu \mathrm{g})$, tetracycline $(30 \mu \mathrm{g})$, ciprofloxacin $(5 \mu \mathrm{g})$, linezolid $(30 \mu \mathrm{g})$, quinupristin/dalfopristin $(15 \mu \mathrm{g})$, teicoplanin $(30 \mu \mathrm{g})$, vancomycin $(30 \mu \mathrm{g})$ and, for high-level aminoglycoside resistance, gentamicin $(120 \mu \mathrm{g})$ and streptomycin $(300 \mu \mathrm{g})$ (Oxoid, Basingstoke, UK) antibiotic discs were studied. Staphylococcus aureus ATCC 25293 was used as quality control microorganism. Minimum inhibitory concentrations (MICs) of vancomycin and teicoplanin were determined using the E-test method and interpreted according to the CLSI guidelines. The strains having MIC values of $32 \mu \mathrm{g} / \mathrm{ml}$ were considered resistant to both antibiotics, those having MICs of $8-16 \mu \mathrm{g} / \mathrm{ml}$ and $16 \mu \mathrm{g} / \mathrm{mL}$ were considered intermediately resistant, and those with MICs of $\leq 4 \mu \mathrm{g} / \mathrm{ml}$ and $\leq 8 \mu \mathrm{g} / \mathrm{ml}$ were regarded as susceptible to vancomycin and teicoplanin, respectively. Enterococcus faecalis ATCC 29212 was used as control microorganism. 


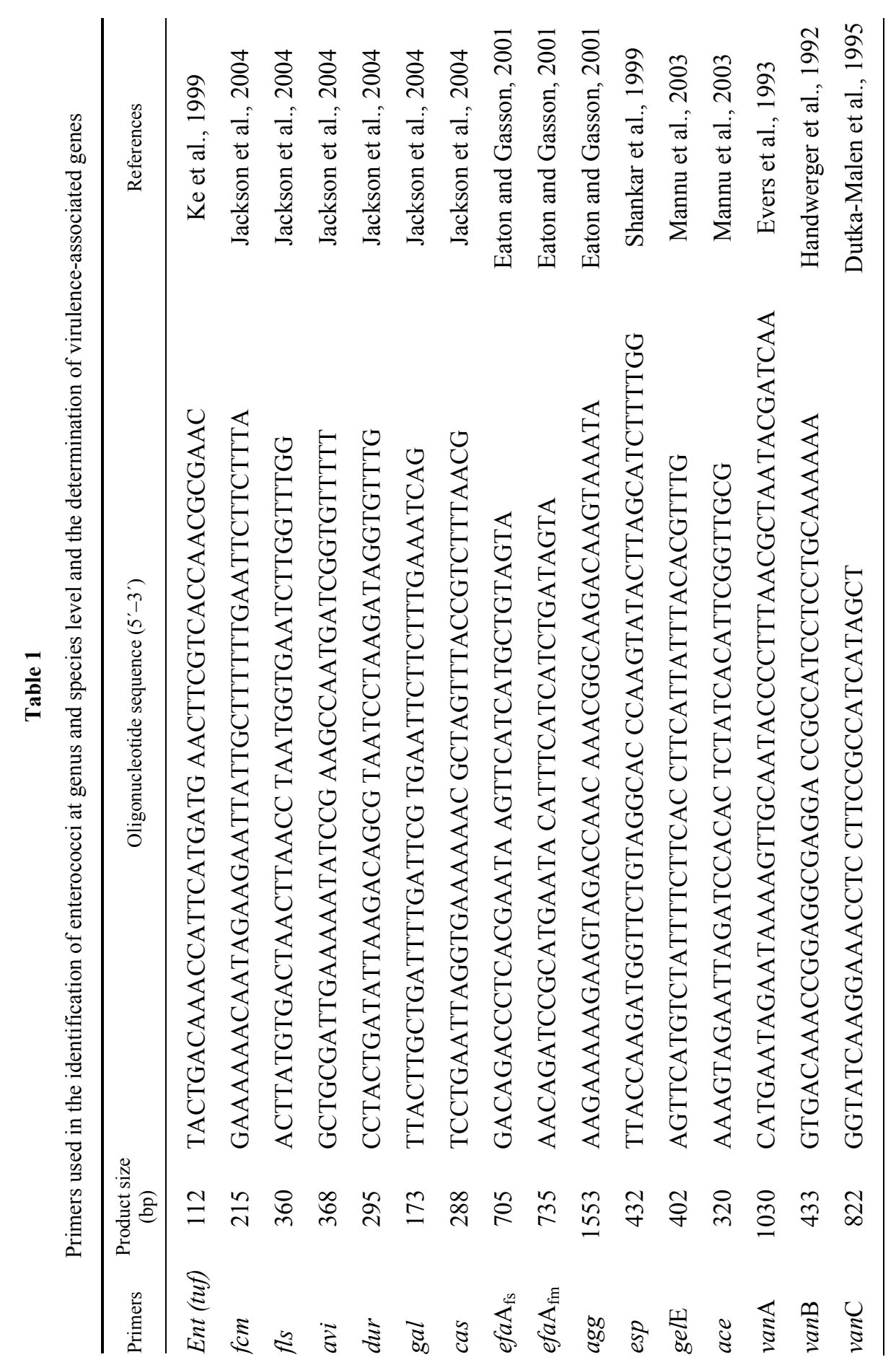




\section{PCR identification and detection}

DNA extraction was performed by using Chelex 100 (Sigma Aldrich, USA). The PCR process was carried out in a ThermoCycler (Runik, SCM 96G). Each $25-\mu 1$ reaction mixture contained $1 \mu 1$ template DNA, $1.25 \mathrm{U}$ of Hot Start Taq DNA polymerase (Bioron, Germany), $10 \mathrm{mM}$ of Tris-HCl pH 8.9, $22 \mathrm{mM}$ of $\mathrm{KCl}, 1.8 \mathrm{mM}$ of $\mathrm{MgCl}_{2}$ (Fermentas, USA), $200 \mu \mathrm{M}$ of dNTPs (Biolabs, UK) and $0.5 \mathrm{mM}$ of each primer (Sentegen, Turkey). The Enterococcus genus-specific primers and the E. faecalis, E. faecium, E. durans, E. gallinarum, E. casselifla$v u s$ and $E$. avium species-specific primers are listed in Table 1 . The presence of $\mathrm{gel \textrm {E }}$, ace, agg and esp genes was tested for all identified isolates, while efa $\mathrm{A}_{\mathrm{fs}}$ and $e f a \mathrm{~A}_{\mathrm{fm}}$ genes were searched only in the E. faecalis and E. faecium isolates. The presence/absence of $\operatorname{van} \mathrm{A}, \operatorname{van} \mathrm{B}$ and $\operatorname{van} \mathrm{C}$ genes was investigated to confirm vancomycin and teicoplanin resistance. The primers, their sequences and related references for PCR conditions are summarised in Table 1.

\section{Results}

In the present survey, 203 enterococci were recovered from 375 food samples $(54.1 \%)$. The average enterococcus count was $3.81 \mathrm{log} \mathrm{cfu} / \mathrm{ml}-\mathrm{g}$ for all tested foodstuffs, $3.48 \mathrm{log} \mathrm{cfu} / \mathrm{g}$ for meat and meat products, $4.14 \mathrm{log} \mathrm{cfu} / \mathrm{ml}-\mathrm{g}$ for milk and dairy products, and $3.41 \mathrm{log} \mathrm{cfu} / \mathrm{g}$ for poultry products. The distribution of enterococcus counts as a function of foodstuffs is shown in Table 2.

According to the PCR identification results, the prevalence of E. faecalis was the highest with an incidence of $53.7 \%$, followed by $E$. faecium $(30.5 \%), E$. durans $(10.3 \%)$, E. avium $(0.5 \%)$ and E. casseliflavus $(0.5 \%)$. Nine isolates were confirmed as Enterococcus spp. but could not be identified at the species level using species-specific primers. PCR identification results obtained for the raw and ready-to-eat foods analysed are summarised in Table 3. A total of 114 enterococcal isolates were recovered from ready-to-eat foods, and 71 of these were isolated from retail cheeses.

The frequency of virulence-associated traits was relatively high among $E$. faecalis isolates and at least one trait was demonstrated in 75 out of the 109 tested isolates. The most commonly detected virulence-associated trait was $e f a_{\mathrm{fs}}$ (38.5\%), followed by gelE (35.7\%), ace (29.4\%), esp (9.2\%) and agg (4.6\%). Thirty-eight isolates had multiple virulence-associated genes. Among these, two isolates from cheese samples were positive for four different genes $\left(e f a_{\mathrm{fs}}, a g g\right.$, gelE, ace and $e f a_{\mathrm{fs}}, e s p, g e l \mathrm{E}$, ace, respectively), 11 were positive for three genes and 25 harboured two genes (Fig. 1). The prevalence of E. faecalis virulenceassociated traits is presented in Table 4. Interestingly, only one E. faecium isolate from milk was positive for the esp gene. Virulence-associated genes were not detected in other Enterococcus isolates. Cheese isolates of E. faecalis harboured 
more virulence determinants than those isolated from other foodstuffs. None of the isolates from poultry products or salamis-sausages was positive for any virulence trait.

Table 2

Distribution and counts of enterococci in foodstuffs

\begin{tabular}{|c|c|c|c|c|}
\hline \multirow{2}{*}{ Sample } & \multirow{2}{*}{$\begin{array}{l}\text { No. of positive } \\
\text { samples (\%) }\end{array}$} & \multicolumn{3}{|c|}{ Enterococcus counts (log cfu/ml-g) } \\
\hline & & Min. & Mean \pm SD & Max. \\
\hline \multicolumn{5}{|l|}{ Meat and meat products } \\
\hline Meat $(\mathrm{n}=30)$ & $13(43)$ & 2.0 & $3.44 \pm 0.76$ & 4.82 \\
\hline Minced meat $(\mathrm{n}=30)$ & $18(60)$ & 2.30 & $3.32 \pm 0.67$ & 4.51 \\
\hline Meatball $(n=25)$ & $20(80)$ & 2.30 & $3.65 \pm 0.55$ & 4.46 \\
\hline Soujuk $(\mathrm{n}=25)$ & $7(28)$ & 2.0 & $3.36 \pm 1.57$ & 6.47 \\
\hline Salami-sausage $(\mathrm{n}=20)$ & $2(10)$ & 2.0 & $3.19 \pm 1.70$ & 4.39 \\
\hline Pastrami $(\mathrm{n}=20)$ & $9(45)$ & 2.0 & $3.62 \pm 1.08$ & 4.71 \\
\hline \multicolumn{5}{|l|}{ Milk and dairy products } \\
\hline Milk $(\mathrm{n}=20)$ & $14(70)$ & 2.0 & $3.70 \pm 0.82$ & 5.23 \\
\hline Cheese $(n=85)$ & $62(73)$ & 2.0 & $4.51 \pm 1.17$ & 6.38 \\
\hline Yoghurt $(n=15)$ & $7(47)$ & 2.0 & $2.81 \pm 1.14$ & 4.53 \\
\hline Butter $(n=15)$ & $9(60)$ & 2.47 & $3.54 \pm 0.87$ & 4.82 \\
\hline $\operatorname{Kefir}(n=15)$ & $5(33)$ & 2.0 & $3.71 \pm 1.05$ & 4.58 \\
\hline \multicolumn{5}{|l|}{ Chicken and poultry products } \\
\hline Chicken $(\mathrm{n}=65)$ & $21(32)$ & 2.0 & $3.37 \pm 0.86$ & 4.59 \\
\hline Poultry products $(\mathrm{n}=10)$ & $1(10)$ & - & $4.41 \pm-$ & - \\
\hline All $(\mathrm{n}=375)$ & $188(50)$ & 2.0 & $3.81 \pm 1.09$ & 6.47 \\
\hline
\end{tabular}

In terms of antibiotic resistance, the highest level of resistance was observed for tetracycline $(21.7 \%)$, followed by quinupristin/dalfopristin $(13.3 \%)$, ciprofloxacin $(2.0 \%)$, penicillin $(2.0 \%)$, linezolid $(1.0 \%)$, ampicillin $(1.0 \%)$, streptomycin $(1.0 \%)$ and gentamicin $(0.5 \%)$. The E. faecalis isolates had a higher resistance rate than other isolates (Table 5). Although one E. faecalis and E. $d u$ rans isolate each exhibited resistance to both vancomycin and teicoplanin by the disk diffusion method, their MIC values were lower than $1 \mu \mathrm{g} / \mathrm{ml}$, suggesting that in reality they were not resistant. This was also observed for one E. durans isolate showing intermediate-level resistance to vancomycin. The absence of van $A$, vanB and van $C$ in these three isolates as tested by PCR confirmed that they were not positive for vancomycin and teicoplanin resistance. The E. avium isolates were sensitive to all tested antibiotics. The multidrug resistance patterns among E. faecalis $(5 / 109,4.6 \%)$ and E. faecium $(2 / 62,3.2 \%)$ isolates demonstrated that, with the exception of one E. faecalis isolate which was resistant to four antibiotics (penicillin, ampicillin, quinupristin/dalfopristin, linezolid), all were resistant to three antibiotics. Two E. faecalis isolates from butter/chicken showed resistance to quinupristin/dalfopristin, tetracycline and streptomycin. In 


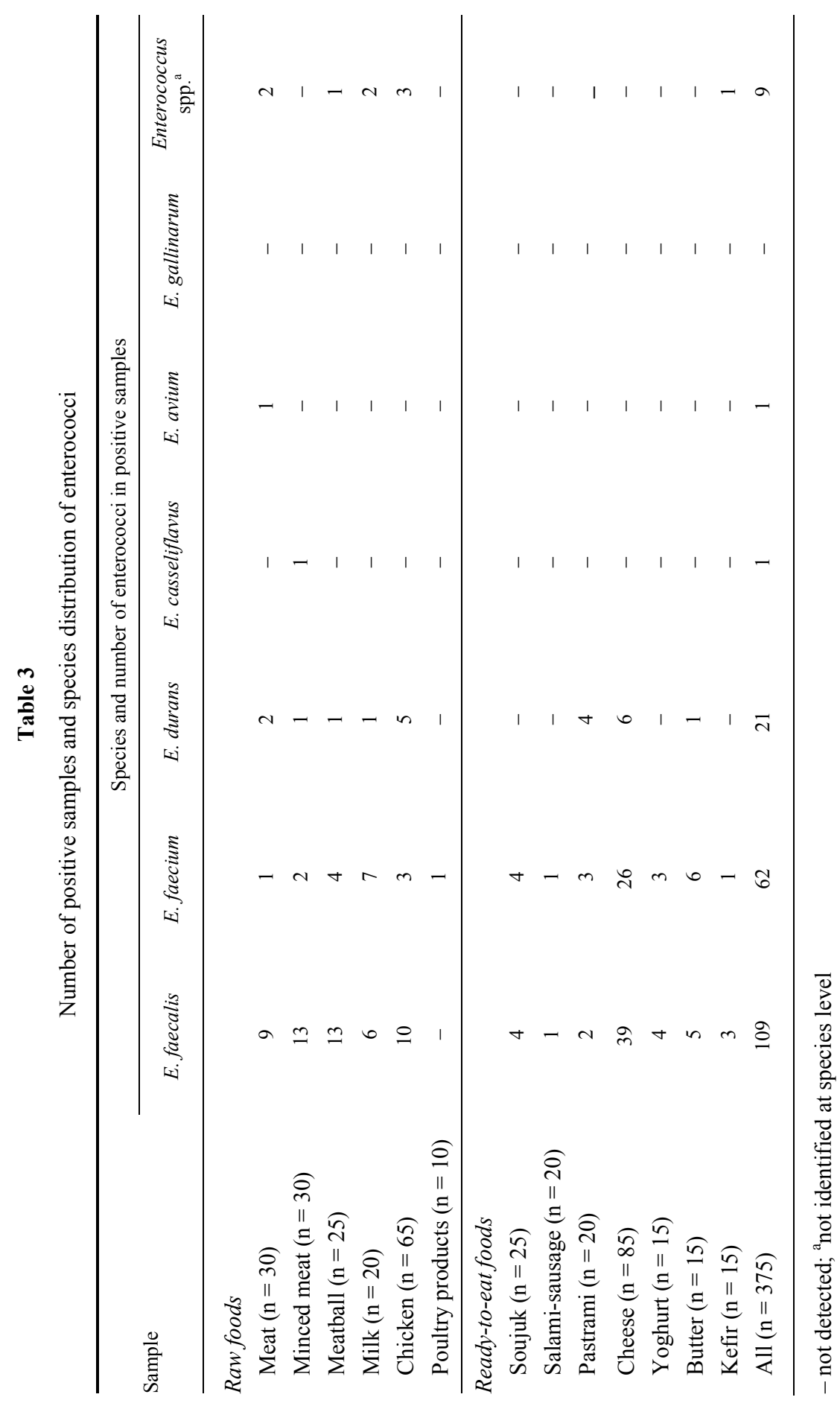


addition, other two E. faecalis isolates and one E. faecium isolate from chicken were resistant to quinupristin/dalfopristin, tetracycline and ciprofloxacin. One meat isolate of E. faecium was found to be resistant to penicillin, ampicillin and tetracycline.

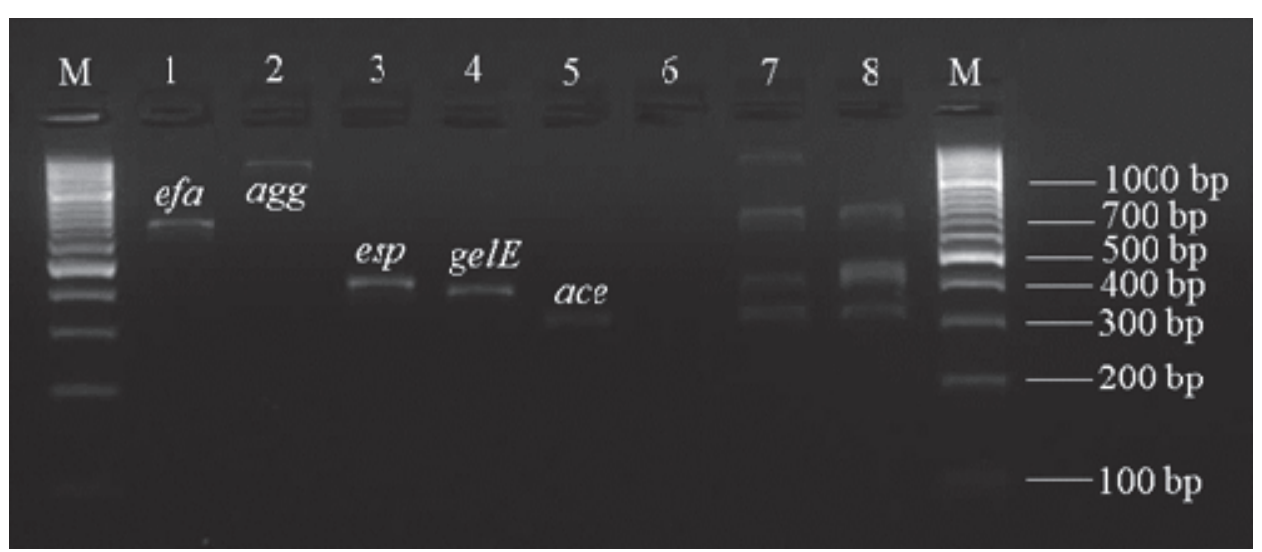

Fig. 1. Virulence-associate genes of enterococci. M: 100 bp DNA ladder; lanes 1: Enterococcus faecalis ATCC 29212; lanes 2-4: E. faecalis MMH 594; lane 5: E. faecalis JH2-2; lane 6: negative control; lane 7: efa-, agg-, gelE- and ace-positive E. faecalis isolate; lane 8: efa-, esp-, gelE- and ace-positive E. faecalis isolate

\section{Table 4}

Distribution of virulence-associated genes of Enterococcus faecalis in foodstuffs

\begin{tabular}{|c|c|c|c|c|c|}
\hline \multirow{2}{*}{$\begin{array}{l}\text { Sample type } \\
\text { (No. of E. faecalis positive samples) }\end{array}$} & \multicolumn{5}{|c|}{ Virulence-associated genes } \\
\hline & $e f a_{f s}$ & agg & $e s p$ & gelE & ace \\
\hline \multicolumn{6}{|l|}{ Meat and meat products } \\
\hline Meat $(n=9)$ & 2 & - & - & 2 & - \\
\hline Minced meat $(n=13)$ & 3 & - & - & 4 & 2 \\
\hline Meatball $(\mathrm{n}=13)$ & 1 & 1 & - & 3 & 8 \\
\hline Soujuk $(n=4)$ & 3 & - & 1 & 1 & - \\
\hline Salami-sausage $(\mathrm{n}=1)$ & - & - & - & - & - \\
\hline Pastrami $(\mathrm{n}=2)$ & 2 & - & - & - & - \\
\hline \multicolumn{6}{|l|}{ Milk and dairy products } \\
\hline Milk $(n=6)$ & 1 & 1 & 2 & 5 & 4 \\
\hline Cheese $(n=39)$ & 24 & 2 & 5 & 13 & 10 \\
\hline Yoghurt $(n=4)$ & 2 & - & - & 2 & 2 \\
\hline Butter $(n=5)$ & 1 & - & 1 & 3 & 2 \\
\hline Kefir $(\mathrm{n}=3)$ & 1 & 1 & - & 1 & - \\
\hline \multicolumn{6}{|l|}{ Chicken and poultry products } \\
\hline Chicken $(\mathrm{n}=10)$ & 2 & - & 1 & 5 & 4 \\
\hline Poultry products $(-)$ & - & - & - & - & - \\
\hline All $(n=109)$ & 42 & 5 & 10 & 39 & 32 \\
\hline
\end{tabular}


Table 5

Antibiotic resistance patterns of Enterococcus species

\begin{tabular}{|c|c|c|c|c|c|c|c|c|c|c|c|c|}
\hline \multirow{2}{*}{ Antibiotics } & \multicolumn{2}{|c|}{$\begin{array}{c}E . \\
\text { faecalis }\end{array}$} & \multicolumn{2}{|c|}{$\begin{array}{c}E . \\
\text { faecium }\end{array}$} & \multicolumn{2}{|c|}{$\begin{array}{c}E . \\
\text { durans }\end{array}$} & \multicolumn{2}{|c|}{$\begin{array}{c}E . \\
\text { casseliflavus } \\
\end{array}$} & \multicolumn{2}{|c|}{$\begin{array}{c}E . \\
\text { avium } \\
\end{array}$} & \multicolumn{2}{|c|}{$\begin{array}{c}\text { Entero- } \\
\text { coccus spp. }\end{array}$} \\
\hline & $\mathrm{R}$ & IM & $\mathrm{R}$ & IM & $\mathrm{R}$ & IM & $\mathrm{R}$ & IM & $\mathrm{R}$ & IM & $\mathrm{R}$ & IM \\
\hline Vancomycin & $1^{\mathrm{a}}$ & - & - & - & $1^{\mathrm{a}}$ & $1^{*}$ & - & - & - & - & - & - \\
\hline Teicoplanin & $1^{\mathrm{a}}$ & - & - & - & $1^{\mathrm{a}}$ & - & - & - & - & - & - & - \\
\hline Penicillin & 1 & - & 3 & - & - & - & - & - & - & - & - & - \\
\hline Ampicillin & 1 & - & 1 & - & - & - & - & - & - & - & - & - \\
\hline Linezolid & 2 & 1 & - & - & - & - & - & - & - & - & - & - \\
\hline $\begin{array}{l}\text { Quinupristin/ } \\
\text { Dalfopristin }\end{array}$ & 21 & 29 & 2 & 2 & 4 & - & - & - & - & - & - & 3 \\
\hline Ciprofloxacin & 2 & 13 & 2 & 14 & - & - & - & 1 & - & - & - & 1 \\
\hline Tetracycline & 27 & 6 & 13 & - & 2 & - & 1 & - & - & - & 1 & - \\
\hline Gentamicin & 1 & 1 & - & - & - & - & - & - & - & - & - & - \\
\hline Streptomycin & 2 & 1 & - & - & - & - & - & - & - & - & - & - \\
\hline
\end{tabular}

R: resistant, IM: intermediately resistant, S: susceptible. ${ }^{a}$ Resistance found by disc diffusion method, but MIC results showed susceptibility in relevant isolates

\section{Discussion}

The incidence of enterococci in foods of animal origin was $54.13 \%$ and the counts varied between 2.0 and $6.5 \mathrm{log} \mathrm{cfu} / \mathrm{ml}-\mathrm{g}$. Similar incidence rates (around 50\%) were also reported by Koluman et al. (2009) and Jahan et al. (2013). Other authors reported lower (23\%; Pesavento et al., 2014) or higher (72\%; Jamet et al., 2012) incidence levels. The study performed by Jamet et al. (2012) revealed enterococcus counts varying between $10^{2} \mathrm{cfu} / \mathrm{g}$ and $10^{8} \mathrm{cfu} / \mathrm{g}$ in cheese samples. Another study indicated that enterococcus counts in fermented foods changed between 4 and $6 \log \mathrm{cfu} / \mathrm{g}$ (Rehaiem et al., 2016). Overall, 56.2\% $(114 / 203)$ of the enterococcus isolates were from ready-to-eat foods, and the prevalence of enterococci in ready-to-eat meat products was $16.7 \%$. ChajeckaWierzchowska et al. (2016b) reported relatively high prevalence $(74.1 \%)$ for the same group of foods in Poland. In our studies reported here, 71 isolates of enterococci were obtained from cheese samples $(n=85)$ collected from the Marmara Region of Turkey. A research conducted in Western Turkey indicated the presence of 95 Enterococcus sp. strains among the 129 isolates obtained from 45 traditional home-made cheeses (Buyukyoruk et al., 2014). These results suggest the ability of enterococci to survive or grow at extreme conditions, even in processed ready-to-eat foods. 
Species-specific multiplex PCR assays confirmed E. faecalis as the most prevalent Enterococcus species in the tested foodstuffs, followed by E. faecium, E. durans, E. casseliflavus and E. avium. Nine Enterococcus isolates giving a positive band with genus-specific primers gave no band with species-specific primers. In agreement with our findings, Pesavento et al. (2014) reported E. faecalis as the dominant species in food samples. However, they isolated four strains of E. gallinarum and found a relatively higher percentage of E. avium. In another study performed on retail foods from Turkey (Koluman et al., 2009), the researchers reported the isolation of E. faecalis and E. faecium only.

Among the meat and meat product samples tested, meatballs were the most contaminated. Moreover, minced meat and fresh meat were also found to be contaminated at relatively high levels. A total of 70 isolates were recovered from meat and meat products ( $42 \mathrm{E}$. faecalis, $15 \mathrm{E}$. faecium, $8 \mathrm{E}$. durans, $1 \mathrm{E}$. casseliflavus, 1 E. avium, 3 Enterococcus spp.). Similarly, studies conducted in Portugal (Barbosa et al., 2010) and Tunisia (Belgacem et al., 2010) also revealed contamination of fermented meat products predominantly with $E$. faecalis and $E$. faecium isolates. In this study we did not isolate E. gallinarum; however, Jahan et al. (2013) isolated E. gallinarum from meat and fermented meat products. The contamination rate of milk and dairy product samples with enterococci was $64.7 \%(97 / 150)$, and the species E. faecalis, E. faecium and E. durans were identified by multiplex PCR. There was no significant difference in $E$. faecalis and $E$. faecium numbers; however, Buyukyoruk et al. (2014) and Hammad et al. (2015) reported a higher prevalence of $E$. faecium in dairy samples.

Five virulence-associated genes were investigated in all the 203 isolates. Virulence traits (except esp) were detected only in the E. faecalis isolates. The esp gene was found only in a E. faecium isolate. Similarly, Barbosa et al. (2010) reported the absence of virulence genes in E. faecium isolates and the presence of the efa, esp, agg and gelE genes in E. faecalis. However, Jahan and Holley (2014) reported the presence of several virulence traits in E. faecalis (efa, esp, gelE, agg, ace) and E. faecium (efa, esp, gelE, agg) strains isolated from meat and meat products. Furthermore, these authors found the ace gene in one E. gallinarum isolate. Another study showed that E. faecium strains from fermented meat products were positive for the gelE and efa genes (Belgacem et al., 2010). A study performed by Hammad et al. (2015) in Egypt demonstrated E. faecalis isolates carrying the agg, esp and gelE genes. Buyukyoruk et al. (2014) suggested the existence of agg, esp and gelE genes in Enterococcus species isolated from farmhouse-produced cheeses.

The antibiotic resistance profiles of the 203 isolates were characterised by the disc diffusion test. Resistance was relatively frequent among E. faecalis isolates: 39 out of 109 isolates were resistant to one or more antibiotics. However, there was no resistance either to vancomycin or teicoplanin. Resistance to tetracycline was remarkable (21\%) among the E. faecium isolates. High tetracycline 
resistance levels were also reported by Jamet et al. (2012), Klibi et al. (2013), Pesavento et al. (2014), Chajecka-Wierzchowska et al. (2016a) and Y1lmaz et al. (2016). Studies performed during the last decade in different countries reported resistance to ciprofloxacin (Belgacem et al., 2010; Jahan et al., 2013; Klibi et al., 2013; Chajecka-Wierzchowska et al., 2016a; Y1lmaz et al., 2016), quinupristin/ dalfopristin (Chajecka-Wierzchowska et al., 2016a), penicillin (Koluman et al., 2009; Jahan et al., 2013; Klibi et al., 2013), ampicillin (Koluman et al., 2009; Klibi et al., 2013), linezolid (Pesavento et al., 2014; Hammad et al., 2015), and streptomycin (Koluman et al., 2009; Jahan et al., 2013; Klibi et al., 2013). Highlevel gentamicin resistance is a subject of discrepancy for Enterococcus infections, since gentamicin has been used in combination with other antibiotics such as vancomycin, ampicillin and penicillin against enterococcal infections (Choi and Woo, 2013). In the present study, one isolate of E. faecalis recovered from yoghurt showed high-level gentamicin resistance. In accordance with these data, isolates from chicken meat (Choi and Woo, 2013) and various foodstuffs (Pesavento et al., 2014) showed resistance to this antibiotic at rates $10.9 \%$ and $21.9 \%$, respectively. Resistance of enterococci to glycopeptide antibiotics is a major concern because vancomycin is the last choice for treating infections caused by Gram-positive bacteria (Cetinkaya et al., 2013). In the present survey, a few isolates exhibited some extent of resistance to vancomycin and teicoplanin by the disc diffusion assay but the presence of genes responsible for these phenotypes could not be confirmed by PCR. In contrast with our results, the presence of vancomycin- and/or teicoplanin-resistant isolates was reported in food samples by some other researchers (Ghidán et al., 2008; Koluman et al., 2009; Pesavento et al., 2014; Hammad et al., 2015; Chajecka-Wierzchowska et al., 2016a; Y1lmaz et al., 2016).

Resistance to multiple antibiotics was widespread among E. faecalis and E. faecium isolates, with $E$. faecalis $(4.6 \%)$ having relatively higher multidrug resistance compared to E. faecium (3.2\%). One cheese isolate of E. faecalis showed resistance to four antibiotics (penicillin, ampicillin, quinupristin/ dalfopristin, linezolid). Various other studies indicated the presence of multidrug-resistant $E$. faecalis and E. faecium isolates from several foods (Koluman et al., 2009; Jamet et al., 2012; Jahan et al., 2013; Chajecka-Wierzchowska et al., $2016 a, b)$. Apart from food isolates, E. faecalis and E. faecium strains obtained from the environment of pig farms were also reported to be resistant to multiple antibiotics (Beshiru et al., 2017).

Interestingly, 74.4\% (29/39) of E. faecalis isolates from 16 ready-to-eat foods (cheese, yogurt, butter, kefir, pastrami, soujuk), having resistance to one or more antibiotics, were found to possess at least one virulence trait as well. Our results indicated that all of the $5 \mathrm{E}$. faecalis isolates presenting a multiresistant profile had at least one virulence gene trait, and two of them were isolated from ready-to-eat foods such as cheese and butter. Furthermore, it was found that a 
cheese isolate of $E$. faecalis resistant to four different antibiotics harboured virulence traits ace and efa, while some of the other multidrug-resistant isolates were positive for virulence factors gelE and ace.

In conclusion, the present research has revealed the presence of Enterococcus species, particularly E. faecalis, in foods of animal origin and determined the virulence-associated traits and/or antibiotic resistance of the isolates. The detection of isolates having pathogenic traits and antibiotic resistance, especially from ready-to-eat foods, provides useful data for risk assessment and indicates that these foods may present a potential public health risk to consumers. The assessment of this public health hazard would, however, need further comparative studies involving human faecal enterococci tested from the same region for the same pathogenicity and antimicrobial resistance traits.

\section{Acknowledgement}

The present study was financially supported by Uludag University Scientific Research Centre [Project number: KUAP (V)-2013/81].

\section{References}

Barbosa, J., Borges, S. and Teixeira, P. (2014): Selection of potential probiotic Enterococcus faecium isolated from Portuguese fermented food. Int. J. Food Microbiol. 191, 144-148.

Barbosa, J., Gibbs, P. A. and Teixeira, P. (2010): Virulence factors among enterococci isolated from traditional fermented meat products produced in the North of Portugal. Food Control 21, 651-656.

Belgacem, Z. B., Abriouel, H., Omar, N. B., Lucas, R., Martinez-Canamero, M., Galvez, A. and Mania, M. (2010): Antimicrobial activity, safety aspects, and some technological properties of bacteriocinogenic Enterococcus faecium from artisanal Tunisian fermented meat. Food Control 21, 462-470.

Beshiru, A., Igbinosa, I. H., Omeje, F. I., Ogofure, A. G., Eyong, M. M. and Igbinosa, E. O. (2017): Multi-antibiotic resistant and putative virulence gene signatures in Enterococcus species isolated from pig farms environment. Microb. Pathog. 104, 90-96.

Buyukyoruk, S., Ayaz, N. D., Gencay, Y. E., Beyaz, D. and Koçak, P. (2014): Species distribution, molecular characteristics and vancomycin resistance gene profiles of Enterococcus sp. isolates from farmhouse cheeses in western Turkey. Int. J. Dairy Technol. 67, 103-109.

Cetinkaya, F., Elal Mus, T., Soyutemiz, G. E. and Cibik, R. (2013): Prevalence and antibiotic resistance of vancomycin-resistant enterococci in animal originated foods. Turk. J. Vet. Anim. Sci. 37, 588-593.

Chajecka-Wierzchowska, W., Zadernowska, A. and Łaniewska-Trokenheim, L. (2016a): Virulence factors, antimicrobial resistance and biofilm formation in Enterococcus spp. isolated from retail shrimps. LWT-Food Sci. Technol. 69, 117-122.

Chajecka-Wierzchowska, W., Zadernowska, A. and Laniewska-Trokenheim, L. (2016b): Diversity of antibiotic resistance genes in Enterococcus strains isolated from ready-to-eat meat products. J. Food Sci. 81, 2799-2807. 
Chajecka-Wierzchowska, W., Zadernowska, A. and Łaniewska-Trokenheim, L. (2017): Virulence factors of Enterococcus spp. presented in food. LWT-Food Sci. Technol. 75, 670-676.

Choi, J. M. and Woo, G. J. (2013): Molecular characterization of high-level gentamicin-resistant Enterococcus faecalis from chicken meat in Korea. Int. J. Food Microbiol. 165, 1-6.

CLSI (Clinical and Laboratory Standards Institute) (2014): Performance Standards for Antimicrobial Susceptibility Testing: Twenty-Fourth Informational Supplement M100-S24, Wayne, PA. pp. 76-79.

Dutka-Malen, S., Evers, S. and Courvalin, P. (1995): Detection of glycopeptide resistance genotypes and identification to the species level of clinically relevant enterococci by PCR. J. Clin. Microbiol. 33, 24-27.

Eaton, T. J. and Gasson, M. J. (2001): Molecular screening of Enterococcus virulence determinants and potential for genetic exchange between food and medical isolates. Appl. Environ. Microb. 67, 1628-1635.

EFSA (European Food Safety Authority) (2013a): Scientific opinion on Cylactin ${ }^{\circledR}$ (Enterococcus $^{\text {(E) }}$ faecium) for calves, lambs and kids for rearing and for fattening. EFSA J. 11, 3097.

EFSA (European Food Safety Authority) (2013b): Scientific opinion on the maintenance of the list of QPS biological agents intentionally added to food and feed (2013 update). EFSA J. 11, 3449 .

Evers, S., Sahm, D. F. and Courvalin, P. (1993): The vanB gene of vancomycin-resistant Enterococcus faecalis V583 is structurally related to genes encoding D-Ala:D-Ala ligases and glycopeptide-resistance proteins vanA and vanC. Gene 124, 143-144.

Fisher, K. and Phillips, C. (2009): The ecology, epidemiology and virulence of Enterococcus. Microbiol. 155, 1749-1757.

Ghidán, Á., Kaszanyitzky, É. J., Dobay, O., Nagy, K., Amyes, S. G. B. and Rozgonyi, F. (2008): Distribution and genetic relatedness of vancomycin-resistant enterococci (VRE) isolated from healthy slaughtered chicken in Hungary from 2001 to 2004. Acta Vet. Hung. 56, 13-25.

Hammad, A. M., Hassan, H. A. and Shimamoto, T. (2015): Prevalence, antibiotic resistance and virulence of Enterococcus spp. in Egyptian fresh raw milk cheese. Food Control 50, 815-820.

Handwerger, S., Perlman, D. C., Altarac, D. and McAuliffe, V. (1992): Concomitant high level vancomycin and penicillin resistance in clinical isolates of enterococci. Clin. Infect. Dis. 14, 655-661.

Hollenbeck, B. L. and Rice, L. B. (2012): Intrinsic and acquired resistance mechanisms in Enterococcus. Virulence 3, 421-433.

Jackson, C. R., Fedorka-Cray, P. J. and Barrett, J. B. (2004): Use of genus and species specific multiplex PCR for identification of enterococci. J. Clin. Microbiol. 42, 3558-3565.

Jahan, M. and Holley, R. A. (2014): Incidence of virulence factors in enterococci from raw and fermented meat and biofilm forming capacity at $25^{\circ} \mathrm{C}$ and $37^{\circ} \mathrm{C}$. Int. J. Food Microbiol. 170, 65-69.

Jahan, M., Krause, D. O. and Holley, R. A. (2013): Antimicrobial resistance of Enterococcus species from meat and fermented meat products isolated by a PCR-based rapid screening method. Int. J. Food Microbiol. 163, 89-95.

Jahan, M., Zhanel, G. G., Sparling, R. and Holley, R. A. (2015): Horizontal transfer of antibiotic resistance from Enterococcus faecium of fermented meat origin to clinical isolates of $E$. faecium and Enterococcus faecalis. Int. J. Food Microbiol. 199, 78-85.

Jamet, E., Akary, E., Poisson, M. A., Chamba, J. F., Bertrand, X. and Serror, P. (2012): Prevalence and characterization of antibiotic resistant Enterococcus faecalis in French cheeses. Food Microbiol. 31, 191-198.

Kafil, H. S., Mobarez, A. M. and Moghadam, M. F. (2013): Adhesion and virulence factor properties of enterococci isolated from clinical samples in Iran. Indian J. Pathol. Microbiol. 56, $238-242$. 
Ke, D., Picard, F. J., Martineau, F., Menard, C. H., Roy, P. H., Ouellette, M. and Bergeron, M. (1999): Development of a PCR assay for rapid detection of enterococci. J. Clin. Microbiol. 37, 3497-3503.

Klibi, N., Ben Said, L., Jouini, A., Slama, K. B., Lopez, M., Sallem, R. B., Boudabous, A. and Torres, C. (2013): Species distribution, antibiotic resistance and virulence traits in enterococci from meat in Tunisia. Meat Sci. 93, 675-680.

Koluman, A., Akan, L. S. and Cakiroglu, F. P. (2009): Occurrence and antimicrobial resistance of enterococci in retail foods. Food Control 20, 281-283.

Mannu, L., Paba, A., Daga, E., Comunian, R., Zannetti, S., Dupre, I. and Sechi, L. A. (2003): Comparison of the incidence of virulence determinants and antibiotic resistance between Enterococcus faecium strains of dairy, animal and clinical origin. Int. J. Food Microbiol. 88, 291-304.

Pesavento, G., Calonico, C., Ducci, B., Magnanini, A. and Lo Nostro, A. (2014): Prevalence and antibiotic resistance of Enterococcus spp. isolated from retail cheese, ready-to-eat salads, ham, and raw meat. Food Microbiol. 41, 1-7.

Pieniz, S., De Moura, T. M., Cassenego, A. P. V., Andreazza, R., Frazzon, A. P. G., Camargo, F. A. O. and Brandelli, A. (2015): Evaluation of resistance genes and virulence factors in a food isolated Enterococcus durans with potential probiotic effect. Food Control 51, 49-54.

Rehaiem, A., Fhoula, I., Slim, A. F., Ben Boubaker, I. B., Chihi, A. B. and Ouzari, H. I. (2016): Prevalence, acquired antibiotic resistance and bacteriocin production of Enterococcus spp. isolated from Tunisian fermented food products. Food Control 63, 259-266.

Shankar, V., Baghdayan, A., Huycke, M. M., Lindahl, G. and Gilmore, M. S. (1999): Infectionderived Enterococcus faecalis strains are enriched in $e s p$, a gene encoding a novel surface protein. Infect. Immun. 67, 193-200.

Yilmaz, E. S., Aslantas, O., Pehlivanlar Onen, S., Turkyilmaz, S. and Kurekci, C. (2016): Prevalence, antimicrobial resistance and virulence traits in enterococci from food of animal origin in Turkey. LWT-Food Sci. Technol. 66, 20-26. 